\title{
TRADUÇÃO DO TEXTO: REFLEXÕES SOBRE OS NEGROS ${ }^{1}$ AUTORA: OLYMPE DE GOUGES - 1788
}

Jasmim Sedie Drigo ${ }^{2}$

Nádia Carrasco Pagnossi ${ }^{3}$

\begin{abstract}
RESUMO: O presente trabalho é uma tradução da obra "Reflexões sobre os negros", da revolucionária francesa Olympe de Gouges, escrito em 1788. A autora apresenta sua experiência com a escravidão, a injustiça e o preconceito que a população negra sofria, mesmo que em uma época de ideias iluministas. Além de refletir sobre esses temas, Gouges critica a Comédie Française, instituição teatral, por não permitir que uma de suas peças de teatro fosse representada ao público, já que continha uma crítica à discriminação racial. A intenção da tradução foi tornar essa obra acessível ao público para ser usada como recurso didático em sala de aula no ensino básico.
\end{abstract}

Palavras-chave: Revolução Francesa. Olympe de Gouges. Escravidão. Iluminismo.

ABSTRACT: The present text is a translation of the work "Reflections on negroes", by the French revolutionary Olympe de Gouges, written in 1788. The author presents her experience with the slavery, the injustice and the prejudice that the black population suffered, although in a time of Enlightenment ideas. In addition to reflecting on these themes, Gouges criticizes the Comédie Française, a theatrical institution, for not allowing one of her plays to be represented to the public, because it contained a critique of racial discrimination. The intention of the translation was to make this work accessible to the public to be used as a didactic resource in the classroom in basic education.

Keywords: French revolution. Olympe de Gouges. Slavery. Enlightenment.

O texto a seguir foi feito a partir da tradução inglesa de Sylvie Molta (1994), sendo comparada com a versão original em francês, escrita pela própria Olympe de Gouges, em 1788. Pensadora e revolucionária icônica, Gouges possui algumas obras que incluem manifestos e peças de teatro. No Brasil, somente a Declaração dos Direitos da Mulher e da Cidadã foi traduzida para o português. A intenção dessa tradução é tornar mais uma

\footnotetext{
${ }^{1}$ Disponível em: http://slavery.uga.edu/texts/literary_works/reflections.pdf

2 Doutoranda em Linguística pela Cornell University (EUA). Mestre em Letras Clássicas pela Universidade de São Paulo.

3 Professora da Secretaria de Educação do Estado de São Paulo. Mestre em Arqueologia pela Universidade Federal de Sergipe.
} 
das obras de Gouges acessível ao público, podendo inclusive ser usada como um recurso didático no ensino básico. Com ideias abolicionistas, a autora reflete acerca da condição dos escravos negros durante o século XVIII, onze anos antes da Revolução Francesa, em uma época de profusão do ideário iluminista, mostrando que os ideais de liberdade, igualdade e fraternidade ainda estavam longe de ser atingidos.

Sempre me interessei pelo destino deplorável da raça negra. Quando meus entendimentos sobre o mundo começaram a desenvolver, naquela idade em que as crianças não pensam em nada seriamente, eu vi uma mulher negra pela primeira vez, e isso me fez refletir e fazer perguntas sobre a sua cor.

As pessoas a quem perguntei sobre isso não satisfizeram minha curiosidade e meu raciocínio. Elas chamavam essas pessoas de brutas, amaldiçoadas por Deus. Na medida em que crescia, percebi claramente que o preconceito e a força as condenavam àquela escravidão terrível, na qual a Natureza não participava de forma alguma; e que os poderosos e injustos interesses dos brancos eram os únicos responsáveis pelo fato.

Convencida por um longo tempo dessa verdade e dessa terrível situação dos escravos, inseri sua história na primeira peça que surgiu da minha imaginação. Muitos homens se interessaram pelo destino dos escravos e se esforçaram para aliviar seu fardo, porém nenhum pensou em deixá-los subir ao palco com suas roupas típicas e sua cor como eu planejava fazer, se a Comédie Française não tivesse se oposto.

Mirza manteve sua língua nativa e nada foi mais tocante que isso. Pareceu-me que deixava a obra mais interessante, e todos os especialistas concordaram, exceto os da Comédie Française. Mas deixemos de lado a minha peça e como ela foi recebida. Agora eu já a apresentei ao público.

Voltemos ao terrível caso dos negros. Quando nos ocuparemos em mudar essa realidade, ou ao menos tentar amenizá-la? Não sei nada sobre as Políticas dos governos, mas elas são justas e mais do que nunca as leis 
da Natureza são ouvidas. Usa-se uma visão favorável em todos primeiros abusos. As pessoas são iguais em todos os lugares. Reis justos não desejam escravos, pois sabem que possuem súditos obedientes, e a França não abandonará os infelizes que fazem das tripas coração em seu sofrimento, desde que a ganância e a ambição têm habitado as ilhas mais remotas. Europeus, sedentos por sangue e pelo metal que a cobiça chama de ouro, fizeram a Natureza mudar nessas ilhas felizes. Pais passaram a repudiar seus filhos, filhos a sacrificar seus pais, irmãos a brigar, e os derrotados foram vendidos como gado no mercado. À que me refiro? Que a escravidão se tornou um comércio nos quatro cantos do mundo.

Comercializar pessoas! Céus! E a Natureza ainda não estremeceu! Se eles são animais, não somos também iguais a eles? Como os Brancos são diferentes dessa raça? Se a diferença está na cor... Por que loiros não reivindicam sua superioridade sobre os morenos, já que esses se parecem aos Mulatos? Essa comparação é tão marcante como do Negro com o mulato. Assim como todas as diversas espécies e tipos de animais, plantas e minerais diferentes que a Natureza produziu, a cor das pessoas também varia. Por que o dia não discute com a noite, o sol com a lua, ou as estrelas com o céu? Tudo é diferente, é diverso, e é nisto que reside a beleza da Natureza. Por que então destruir sua obra?

Não é a humanidade a obra-prima mais bonita? Os otomanos exploram os brancos da mesma forma que exploramos os negros. Não os acusamos de serem bárbaros ou desumanos, e somos igualmente cruéis com pessoas cujo único meio de resistência é a submissão.

Mas quando a submissão começa a enfraquecer, o que resulta do bárbaro despotismo dos moradores das ilhas e índios do Oeste (antilhanos)? Revoltas de todos os tipos, carnificina incrementada com a ação de tropas, envenenamentos e tudo o que o homem pode fazer quando ele se revolta. Não parece monstruoso que os Europeus, tendo adquirido vastas plantações pela exploração de outros, venham açoitando Negros noite e dia? Essas pobres almas miseráveis cultivariam seus próprios campos se lhes fossem concedidas mais liberdade e gentileza. 
Não é o seu destino um dos mais cruéis, seu trabalho o mais duro, além dos Brancos os castigarem com horríveis punições, e pelo menor erro? Fala-se sobre mudarmos sua sina, sobre encontrar meios de facilitar suas vidas, sem temer que essa raça de homens use indevidamente a liberdade plena e que continuem subordinados.

Eu não entendo nada sobre Política. Alguns preveem que a liberdade generalizada faria com que os homens Negros fossem tão essenciais quanto os Brancos, e assim que eles fossem autorizados a ser senhores de seus próprios destinos, poderiam ser então senhores de suas vontades e criar seus filhos ao seu lado. Eles seriam mais aplicados em seu trabalho e mais zelosos. A intolerância não mais os atormentaria, e o direito a ascenderem como os outros os faria mais sábios e mais humanos. Conspirações mortais já não seriam temidas. Eles cultivariam livres suas próprias terras, como os Camponeses Europeus, e não deixariam suas terras para migrarem para Nações estrangeiras. A liberdade dos Negros fará com que alguns abandonem seus países, porém seriam muito menos do que os habitantes dos campos franceses. Os jovens Aldeões mal chegam à idade adulta, e a força e a coragem são requisitadas para chegarem à Capital (a Paris) e assumirem os nobres ofícios de Lacaios, ou de Porteiros. Existem centenas de Criados para uma só vaga, enquanto em nossos campos faltam lavradores.

Essa liberdade produzirá um grande número de ociosos, infelizes e malvados de todas as espécies. É possível que cada nação crie limites recomendáveis e saudáveis para seu Povo; essa é a arte dos Soberanos e dos Estados Republicanos. Meus instintos naturais poderiam ajudar a encontrar uma solução, mas me refrearei de a apresentar. Falta-me mais instrução e esclarecimento sobre as Políticas dos Governos. Como já disse, não sei nada, é por acaso que algumas das minhas observações sejam boas ou más. Mais do que ninguém, devo me interessar pelo destino desses desafortunados Negros, porque faz cinco anos desde que escrevi uma peça baseada em sua história trágica.

Tenho apenas alguns conselhos para dar aos da Comédie Francaise, e é o único favor que Ihes pedirei na minha vida: que adotem a cor e o traje 
da raça Negra. Nunca a ocasião foi mais oportuna, e espero que a Reprodução desse Drama produza efeito a favor dessas vítimas da ambição. Os trajes contribuirão muito no interesse pela Peça, que inspirará as penas e corações de nossos melhores escritores. Meu objetivo será atingido, minha ambição satisfeita, e a Comédie Française será elevada em vez de se desonrar na questão da cor.

Minha alegria seria imensurável se eu visse a Representação da minha Peça como sempre desejei. Esse fraco esboço requereria uma comovente pintura para a posteridade. Pintores ambiciosos o suficiente para pintarem os painéis poderiam ser considerados como os Fundadores da Humanidade, e os mais sábios e úteis, e estou convencida de que eles favoreceriam o tema dessa fraca Peça, através de sua expressão dramática.

Então, Senhoras e Senhores, representem minha Peça, que ela já esperou tempo suficiente. Como vocês pediram, ela foi publicada. Eu me uno a cada Nação para pedirmos pela sua representação, e estou certa de que eles não me desapontarão. Essa sensibilidade que poderia ser considerado como orgulho próprio, se visto em outros, é resultado do impacto que o protesto público a favor dos Negros tem sobre mim. Qualquer leitor que aprecie meu trabalho será convencido dessa verdade.

Enfim, passarei aos últimos avisos, que são caros a mim, mas acredito que tenho direito a elas. Adeus, Senhoras e Senhores, depois das minhas observações, representem minha peça se Ihes parecer apropriada; não devo ir aos ensaios. Eu transfiro todos os direitos ao meu filho; que ele faça um bom uso deles e se proteja de se tornar um Escritor da Comédie Française. Se ele acreditar em mim, jamais tocará em uma pena para escrever Literatura.

\section{Referências}

GOUGES, Olympe de. Declaração dos direitos da mulher e da cidadã. Interthesis: Revista Internacional Interdisciplinar, Florianópolis, v. 4, n. 1, jan./jun. 2007. 
GOUGES, Olympe de. Réflexions sur les hommes nègres. Her Fuvres de Madame de Gouges, Paris, v. 3, p. 92-99, 1788.

MOLTA, Sylvie. Reflections on negroes. In: KADISH, Doris Y. et al. (Ed.). Translating slavery: gender and race in French women's writing, 17831823. Ohio: Kent State University, 1994. (Translation Studies, n. 2). 